\title{
The metric dimension of strong product graphs
}

\section{Juan A. Rodríguez-Velázquez ${ }^{1}$, Dorota Kuziak ${ }^{1}$, Ismael G. Yero ${ }^{2}$ and José M. SIGARRETA ${ }^{3}$}

\section{ABSTRACT.}

For an ordered subset $S=\left\{s_{1}, s_{2}, \ldots s_{k}\right\}$ of vertices in a connected graph $G$, the metric representation of a vertex $u$ with respect to the set $S$ is the $k$-vector $r(u \mid S)=\left(d_{G}\left(v, s_{1}\right), d_{G}\left(v, s_{2}\right), \ldots, d_{G}\left(v, s_{k}\right)\right)$, where $d_{G}(x, y)$ represents the distance between the vertices $x$ and $y$. The set $S$ is a metric generator for $G$ if every two different vertices of $G$ have distinct metric representations with respect to $S$. A minimum metric generator is called a metric basis for $G$ and its cardinality, $\operatorname{dim}(G)$, the metric dimension of $G$. It is well known that the problem of finding the metric dimension of a graph is NP-Hard. In this paper we obtain closed formulae and tight bounds for the metric dimension of strong product graphs.

\section{REFERENCES}

[1] Brigham, R. C., Chartrand, G., Dutton, R. D. and Zhang, P., Resolving domination in graphs, Math. Bohem., 128 (2003), 25-36

[2] Cáceres, J., Hernando, C., Mora, M., Pelayo, I. M., Puertas, M. L., Seara, C. and Wood, D. R., On the metric dimension of Cartesian product of graphs, SIAM J. Discrete Math., 21 (2007), 273-302

[3] Chartrand, G., Eroh, L., Johnson, M. A. and Oellermann, O. R., Resolvability in graphs and the metric dimension of a graph, Discrete Appl. Math., 105 (2000), 99-113

[4] Chartrand, G., Salehi, E. and Zhang, P., The partition dimension of a graph, Aequationes Math., 59 (2000), $45-54$

[5] Harary, F. and Melter, R. A., On the metric dimension of a graph, Ars Combin., 2 (1976), 191-195

[6] Imrich, W. and Klavžar, S., Product Graphs, Structure and Recognition, Wiley-Interscience, 2000

[7] Johnson, M. A., Structure-activity maps for visualizing the graph variables arising in drug design, J. Biopharm. Statist., 3 (1993), 203-236

[8] Johnson, M. A., Browsable structure-activity datasets, in Advances in Molecular Similarity, (R. Carbó-Dorca and P. Mezey, Eds.), JAI Press Connecticut, (1998) pp. 153-170

[9] Khuller, S., Raghavachari, B. and Rosenfeld, A., Landmarks in graphs, Discrete Appl. Math., 70 (1996), $217-229$

[10] Kratica, J., Kovačević-Vujčić, V., Čangalović, M. and Stojanović, M., Minimal doubly metric generators and the strong metric dimension of Hamming graphs, Appl. Anal. Discrete Math., 6 (2012), 63-71

[11] Kuziak, D., Yero, I. G. and Rodríguez-Velázquez, J. A., On the strong metric dimension of corona product graphs and join graphs, Discrete Appl. Math., 161 (2013), 1022-1027

[12] May, T. R. and Oellermann, O. R., The strong dimension of distance-hereditary graphs, J. Combin. Math. Combin. Comput., 76 (2011), 59-73

[13] Oellermann, O. R. and Peters-Fransen, J., The strong metric dimension of graphs and digraphs, Discrete Appl. Math., 155 (2007), 356-364

[14] Okamoto, F., Phinezyn, B. and Zhang, P., The local metric dimension of a graph, Math. Bohem., 135 (2010), 239-255

[15] Sebő, A. and Tannier, E., On metric generators of graphs, Math. Oper. Res., 29 (2004), 383-393

[16] Slater, P. J., Leaves of trees, Proceeding of the 6th Southeastern Conference on Combinatorics, Graph Theory, and Computing, Congr. Numer., 14 (1975), 549-559

Received: 19.07.2013; In revised form: 28.04.2014; Accepted: 30.04.2014

2010 Mathematics Subject Classification. 05C12, 05C38, 05C69, 05 C76.

Key words and phrases. Metric generator, metric basis, metric dimension, strong product graph, resolving set.

Corresponding author: Dorota Kuziak; dorota.kuziak@urv.cat 
[17] Yero, I. G. and Rodríguez-Velázquez, J. A., A note on the partition dimension of Cartesian product graphs, Appl. Math. Comput., 217 (2010), 3571-3574

[18] Yero, I. G., Kuziak, D. and Rodríguez-Velázquez, J. A., On the metric dimension of corona product graphs, Comput. Math. Appl., 61 (2011), 2793-2798

${ }^{1}$ Departament D’ENGinyeria Informàtica i MatemÀtiQues

UNIVERSITAT ROVIRA I VIRGILI

Av. Països Catalans 26, 43007 Tarragona, Spain

E-mail address: juanalberto.rodriguez@urv.cat, dorota.kuziak@urv.cat

2 Departamento de Matemáticas, Escuela Politécnica Superior de Algeciras UNIVERSIDAD DE CÁDIZ

Av. Ramón Puyol S/N, 11202 Algeciras, Spain

E-mail address: ismael.gonzalez@uca.es

${ }^{3}$ UNIVERSIDAD AUTÓNOMA DE GUERRERO

FACULTAD DE MATEMÁticas

Carlos E. Adame 5, Col. la Garita, Acapulco, Guerrero, México

E-mail address: josemariasigarretaalmira@hotmail.com 